Saudi Journal of Oral and Dental Research

Abbreviated Key Title: Saudi J Oral Dent Res

ISSN 2518-1300 (Print) |ISSN 2518-1297 (Online)

Scholars Middle East Publishers, Dubai, United Arab Emirates

Journal homepage: https://saudijournals.com/sjodr

\title{
Knowledge and Attitude of Dental Professionals towards Basic Life Support
}

\author{
Muhammad Ilyas $^{1 *}$, Ain ul Momina ${ }^{2}$, Anum Saleem ${ }^{3}$, Gul Shaikh ${ }^{4}$, Amina Tariq ${ }^{5}$ \\ ${ }^{1}$ Associate Professor of Orthodontics; De' Montmorency College of Dentistry, Lahore Pakistan \\ ${ }^{2}$ Assistant Professor of Community Medicine at King Edward Medical University, Lahore Pakistan \\ ${ }^{3}$ Dentist; De' Montmorency College of Dentistry, Lahore Pakistan \\ ${ }^{4}$ Assistant Professor of Health Professions Education; National University of Medical Sciences, Rawalpindi Pakistan \\ ${ }^{5}$ Postgraduate research coordinator; University College of Dentistry, The University of Lahore Pakistan
}

\author{
DOI: $10.36348 /$ sjodr.2020.v05i06.007 \\ | Received: 11.06 .2020 | Accepted: 22.06.2020 | Published: 28.06.2020 \\ *Corresponding author: Muhammad Ilyas
}

\section{Abstract}

Basic life support (BLS) is a resuscitative emergency care provided to victims of medical conditions which could be life threatening, until they can be given full medical care at a hospital. BLS ensures maintenance of clear airway, support of breathing and blood circulation in case of cardiac arrest .BLS is an important aspect of daily emergency medical treatment which ,if provided correctly can save a life. Objective: the objective of the study was to evaluate the knowledge and attitude of dental professionals towards basic life support in Lahore, Punjab, Pakistan. Method: The study was cross sectional in nature. A questionnaire was used to collect data from 174 dental students of government and private sector in Lahore, which included questions on various aspects of basic life support including basic knowledge about treatment procedures and general attitude of dental students towards training. Dully filled questionnaires were collected, analyzed and presented as pie chart and graphs. Results: In this study, 51\% of participants showed lack of basic knowledge about basic life support and none of the participants were able to answer all of the asked questions .76\% of students admitted that they were never educated about basic life support but $96 \%$ of participants agreed that they should be trained for providing basic life support. Conclusion: It was concluded that the dental students and practitioners of Lahore have a healthy attitude towards training of basic life support but a considerable number were lacking in general knowledge of cardiopulmonary resuscitation (CPR) and other critical procedures of basic life support. Despite encountering medical emergencies in dental clinical set ups, they were never trained in basic life support. Theoretical and practical training of BLS should be made a compulsory part of dental courses in the region to rectify the situation.

Keywords: basic life support, cardiopulmonary resuscitation

Copyright @ 2020: This is an open-access article distributed under the terms of the Creative Commons Attribution license which permits unrestricted use, distribution, and reproduction in any medium for non-commercial use (NonCommercial, or CC-BY-NC) provided the original author and source are credited.

\section{INTRODUCTION}

Cardiovascular diseases are the prominent cause of deaths across the world, with sudden cardiac arrest making up half of these mortalities. Survival after sudden cardiac arrest depends on early intervention, cardiopulmonary resuscitation and timely defibrillation with automated external defibrillator (AED)[1,2]. External cardiac compressions (ECC) only make third of the original cardiac output and therefore cerebral perfusion. ECC depends on the competence of the rescuer because for a short amount of time this cerebral perfusion is enough but any errors made in ECC can highly affect the outcome of resuscitation. Any delay in the commencement of ECC should be minimized because irreversible neuronal damage can occur in just 3 to 4 minutes of oxygen deprivation [3, 4]. Regretfully, it is stated that only 15 to $30 \%$ of victims receive effective cardiopulmonary resuscitation and for every minute worth of postponement in CPR or defibrillation there is a reduction in the probabilities of survival by 7 to $10 \%$. This further supports the importance of BLS [1, $5]$.

American heart association has updated the procedures for CPR and emergency cardiac care since 1966 when it was first published by national academy of sciences. CPR is used when the heart has stopped pumping on its own. This technique combines two elements; chest compressions and artificial ventilation with the intention of trying to manually protect the integral brain functionality until spontaneous circulation and breathing is restored in the victim of cardiac arrest. This is the basis of basic life support $[6,7]$. 
Though cardiac arrests are rare but still witnessed in dental clinical set ups. Several of the drugs administered e.g. local anesthetics, sedatives, analgesics, and parenteral antibiotics can trigger allergic reactions or vasovagal syncope. This hypersensitivity reaction can cause an acute life threatening condition. Patients with mental instability and children can aspirate endodontic instruments if lying in supine position or sedated. Fear of pain can cause anxiety attacks [8].

Little information has been published on the competence of dentists in basic life support and occurrence of life threatening emergencies in Pakistan. In 1975, Young reported a survey of 300 dentists in England and his results concluded that for every two practitioners one was likely to face a dental emergency. Moreover, one in every six dentists will encounter cardiac arrest. $71 \%$ indicated interest in receiving resuscitation courses. In 1986 USA did a survey of 1605 dentists and almost $96 \%$ felt that basic life support should be a part of dental curriculum [9].

This signifies the need of awareness among dental professionals about how to deal with medical emergencies. It's been noticed that there is recent rise in medico legal cases due to increase in number of deaths in dental chair [10]. In this study, evaluation of knowledge and attitude of dental students in Lahore about basic life support was the purpose.

\section{METHODOLOGY}

A cross sectional study survey was conducted in government and private dental colleges of Lahore. Lahore is one of the two cities in Punjab where government dental college is established and where most private dental colleges can be found The sample size was based on judgmental sampling.174 dental practitioner were selected for study.

\section{INCLUSION CRITERIA}

Males and females both

Young adults (20-29yr)

Post graduates

House officers

Under graduates from 4th year

There was not any exclusion criterion in the study. A self-administered questionnaire consisting of 22 questions was undertaken to explore the attitude and acquaintance of dental students towards basic life support. One of the authors approached the dental students herself to get the questionnaires filled. After getting the informed consent students were briefed about the aim and objective of the study, and assured that the obtained knowledge will remain anonymous and will be used for research purposes only. A thoroughly discussed questionnaire with 22 questions based on American heart association's BLS was used to assess the knowledge and attitude of 200 dental students. Attitude based questions consisted on yes/no answers. Knowledge was assessed with multiple choice questions pattern. Third type of questions was open ended with marked space left for the students to fill. Out of 200 distributed questionnaires 174 were completely filled and were included in the data for the study. Data was arranged and analyzed and is presented in tabulated form.

\section{RESULTS}

The study was conducted with 174 students which included 40 post graduates, 46 house officers and 89 under graduates, participants who had the freshest knowledge of their training. The results show none of the participants had complete knowledge of basic life support protocols.

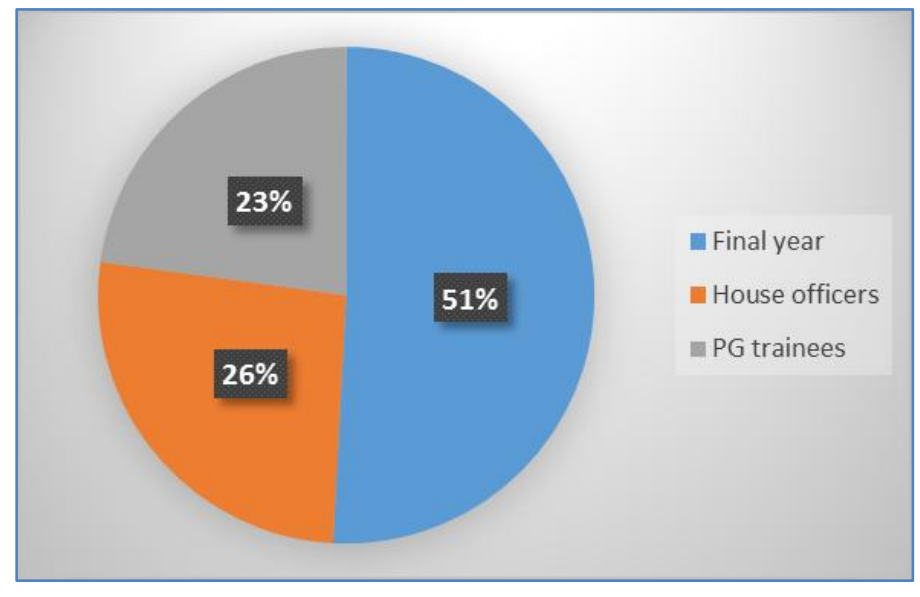




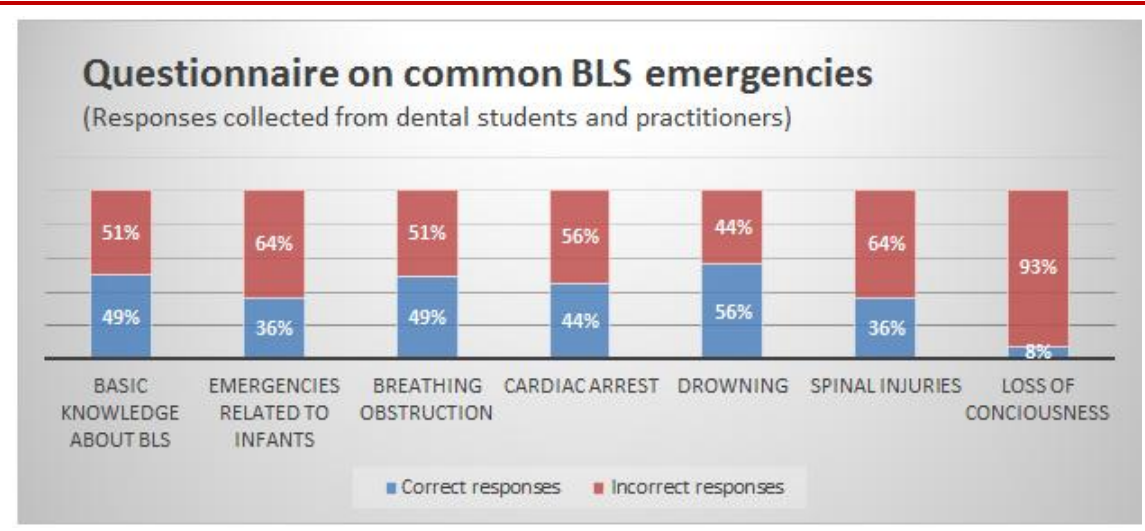

$51 \%$ of students answered incorrectly about common knowledge of BLS emergencies.64\% of participants were incompetent at handling emergency cases of infants and children. $80 \%$ of the students did not know how asses an infant or child's pulse at the brachial artery. And only 51\% knew that the correct time for assessing pulse is more than $5 \mathrm{~s}$ but less than 10 s. Only $45 \%$ of students knew the correct way to open the airway is jaw thrust in a patient of suspected cervical spine trauma. $85 \%$ of students knew how to manage a mild airway obstruction but $74 \%$ did not know how to treat severe airway obstruction. $84 \%$ of participants knew what CPR is. But only $29 \%$ of students knew that C-A-B (circulation, airway, breathing) is the new recommended AHA EU guideline so as to maintain blood supply to vital organs. $90 \%$ of participants did not know that 100 compressions per minute are required for cardiopulmonary resuscitation, and for every 30 times that the chest compressions are performed you execute two rescue breaths which is 15:2 in infants if two rescuers are available. It was found that $79 \%$ of participants knew how to assess restored ventilation. Only $40 \%$ of participants knew that main reason for cardiac arrest and death in victims who drown and choke is hypoxia, and rescue breathing should be performed as fast as can be provided in these situations, whereas for victims of ventricular failure (VF) cardiac arrest the process of performing chest compressions and defibrillation are more significant. $64 \%$ of participants admitted that they did not know how to approach a victim of spinal injury. According to a survey in northern England syncope is the most frequent emergency (1.9 cases per dentist per year) and only $7 \%$ of students knew that for approaching any medical emergency "shouting for help" is the first step.

As for attitude towards basic life support $51 \%$ of participants confirmed that they encountered medical emergency in dental clinical setup. $66 \%$ of students were too anxious to handle the emergency themselves but $46 \%$ participants admitted that their seniors were able to manage the emergency $.95 \%$ students reported that their dental facilities did not have automated external defibrillator (AED). $96 \%$ of participants agreed that they should be trained for basic life support and regrettably $76 \%$ admitted that they were never trained for providing basic life support and it was not a part of their daily dental curriculum.

\section{DISCUSSION}

Life threatening emergencies can occur at anytime and anywhere and most deadly of all is cardiopulmonary arrest (CPA). To increase survival chances of a CPA victim immediate CPR is extremely necessary as it restores the vital functions of the body. It maintains the appropriate level of tissue oxygenation in the victim until emergency facilities become available most importantly defibrillation [11]. CPR with emergency medical services and advanced life support can improve the outcome of cardiac arrest. Though many dentists insist that they have never witnessed CPA as health professionals it's their responsibility to manage the emergency efficiently and effectively if presented. Deaths in dental chair due to cardiac arrest are witnessed and the amount of medico legal charges against dentist is increased in number [12]

This study was undertaken to evaluate the knowledge and attitude of dental students about BLS/CPR so that a plan could be formed for BLS training from early years of dentistry.

This study showed that the candidates had inadequate knowledge of BLS. None of the participants were able to answer all the questions properly. Almost all of them were never trained for CPR or EMS. Although $96 \%$ of participants showed positive attitude towards learning of BLS. Most of the dental students were only reluctant because of the fear of giving ineffective treatment or further harming the patient.

Many countries include BLS training as part of their daily dental curriculum. In USA more of the states are now requiring BLS competence for the dentists to be registered and 22 states now require annual renewal of the certification $[4,13]$.

Girdler et al found the total occurrence of emergency event (excluding syncope) is $0.7 \%$ cases per dentist per year. It was identified that a mere $20.8 \%$ felt that they were capable to diagnose the reason of collapse during dental surgery [10,14]. Similar to our 
study Iran, Brazil and India are not well prepared to handle medical emergencies in dental clinical set ups $[10,15,16]$. In some studies conducted by Skopa et al. [17] and Laurant et al. [18] $50 \%$ of the participants believed they could perform CPR.

This kind of difference could be because of different methodologies of surveys, which is also a limitation of this study. It seems that practical analysis is more accurate than self-assessment questionnaire for BLS skills. For instance Hussain et al. [19] used practical examination for his analysis and all of his participants failed.

Theoretical knowledge with practical demonstration and regular practice are determining factors for perfect BLS skills. This should be ensured that future training of emergency care should target deficiencies of dental students in basic life support.

\section{CONCLUSION}

Our study concluded that emergency care knowledge is highly lacking in dental practitioners but almost all students have a very positive attitude towards training. So, this should be included in their curriculum from early years.

\section{REFERENCES}

1. Sasson, C., Rogers, M. A., Dahl, J., \& Kellermann, A. L. (2010). Predictors of survival from out-ofhospital cardiac arrest: a systematic review and meta-analysis. Circulation: Cardiovascular Quality and Outcomes, 3(1), 63-81.

2. Goddard, K. B., Eppert, H. D., Underwood, E. L., McLean, K. M., Finks, S. W., \& Rogers, K. C. (2010). Basic life support and cardiopulmonary resuscitation training for pharmacy students and the community by a pharmacy student committee. American journal of pharmaceutical education, 74(6).

3. Chapman, P. J. (1997). Medical emergencies in dental practice and choice of emergency drugs and equipment: a survey of Australian dentists. Australian dental journal, 42(2), 103-108.

4. Adult advanced life support - Guidelines. (1993). Med J A u s t, 159:616-21.

5. Jamalpour, M. R., Asadi, H. K., \& Zarei, K. (2015). Basic life support knowledge and skills of Iranian general dental practitioners to perform cardiopulmonary resuscitation. Nigerian medical journal: journal of the Nigeria Medical Association, 56(2), 148.

6. American Heart Association. (1992). Guidelines for cardiopulmonary resuscitation and emergency cardiac care. Part III - Adult advanced cardiac life support. J Am Med Assoc, 268:2199- 201.
7. Khalid, U., \& Juma, A. A. M. (2010). Paradigm shift:'ABC'to'CAB'for cardiac arrests. Scandinavian journal of trauma, resuscitation and emergency medicine, 18(1), 59.

8. Malamed, S.F. (1993). Medical emergencies in the dental office. 4th edn. St Louis: Mosby, 424.

9. Chapman, P. J. (1995). A questionnaire survey of dentists regarding knowledge and perceived competence in resuscitation and occurrence of resuscitation emergencies. Australian dental journal, 40(2), 98-103.

10. Baduni, N., Prakash, P., Srivastava, D., Sanwal, M. K., \& Singh, B. P. (2014). Awareness of basic life support among dental practitioners. National journal of maxillofacial surgery, 5(1), 19.

11. Public Access Defibrillation Trial Investigators. (2004). Public-access defibrillation and survival after out-of-hospital cardiac arrest. New England Journal of Medicine, 351(7), 637-646.

12. Kumar, K., \& Mukhi, C. S. (2014). Basic Resuscitation in Dental Office: A Review. IJSS Case Reports \& Reviews, 1(4), 22-25.

13. Peskin, R. M., \& Siegelman, L. I. (1995). Emergency cardiac care. Moral, legal, and ethical considerations. Dental clinics of North America, 39(3), 677-688.

14. Girdler, N. M., \& Smith, D. G. (1999). Prevalence of emergency events in British dental practice and emergency management skills of British dentists. Resuscitation, 41(2), 159-167.

15. Arsati, F., Montalli, V. Â., Flório, F. M., Ramacciato, J. C., da Cunha, F. L., Cecanho, R., ... \& Motta, R. H. L. (2010). Brazilian dentists' attitudes about medical emergencies during dental treatment. Journal of dental education, 74(6), 661666.

16. Jamalpour, M. R., Asadi, H. K., \& Zarei, K. (2015). Basic life support knowledge and skills of Iranian general dental practitioners to perform cardiopulmonary resuscitation. Nigerian medical journal: journal of the Nigeria Medical Association, 56(2), 148.

17. Sopka, S., Biermann, H., Druener, S., Skorning, M., Knops, A., Fitzner, C., \& Beckers, S. (2012). Practical skills training influences knowledge and attitude of dental students towards emergency medical care. European Journal of Dental Education, 16(3), 179-186.

18. Laurent, F., Augustin, P., Nabet, C., Ackers, S., Zamaroczy, D., \& Maman, L. (2009). Managing a cardiac arrest: evaluation of final-year predoctoral dental students. Journal of dental education, 73(2), 211-217.

19. Hussain, I., Matthews, R. W., \& Scully, C. (1992). Cardiopulmonary resuscitation skills of dental personnel. British dental journal, 173(5), 173-174. 